Weert, J.C.M. van, Dulmen, A.M. van, Spreeuwenberg, P., Bensing, J.M., Ribbe, M.W. The effects of the implementation of snoezelen on the quality of working life in psychogeriatric care. International Psychogeriatrics: 2005, 17(3), 407-425

\begin{tabular}{|l|l|}
\hline $\begin{array}{l}\text { Postprint } \\
\text { Version }\end{array}$ & 1.0 \\
\hline $\begin{array}{l}\text { Journal website } \\
\text { Pubmed link }\end{array}$ & $\underline{\text { http://dx.doi.org/10.1017/S1041610205002176 }}$ \\
\hline DOI & $\underline{\text { doi:/10.1017/S1041610205002176 }}$ \\
\hline
\end{tabular}

This is a NIVEL certified Post Print, more info at http://www.nivel.eu

\title{
The effects of the implementation of snoezelen on the quality of working life in psychogeriatric care
}

\author{
Julia C. M. VAN WeERT, ${ }^{1}$ AleXANDRA M. VAN DULMEN, ${ }^{1}$ PETER M. M. \\ SPREEUWENBERG, ${ }^{1}$ JOZIEN M. BENSING ${ }^{1,2}$ AND MIEL W. RIBBE ${ }^{3}$ \\ ${ }^{1}$ NIVEL (Netherlands Institute for Health Services Research), Utrecht, the Netherlands \\ ${ }^{2}$ Department of Psychology, University of Utrecht, the Netherlands \\ ${ }^{3}$ Department of Nursing Home Medicine, Institute for Research in Extramural Medicine \\ (EMGO Institute) of the VU University Medical Center, Amsterdam, the Netherlands
}

\begin{abstract}
Background: Dementia among nursing home residents is often accompanied by high care dependency and behavioral disturbances, resulting in an increased workload for the caregivers. Snoezelen, integrated into 24-hour dementia care, is an approach that might improve the quality of working life of dementia caregivers. This study aims to investigate the effectiveness of integrated snoezelen on work-related outcomes (workload and psychological outcomes) of caregivers in psychogeriatric nursing homes.
\end{abstract}

Methods: A quasi-experimental pre- and post-test design was used, comparing six psychogeriatric wards that implemented snoezelen in 24-hour care to six control wards that continued giving usual care. One hundred and twentynine Certified Nursing Assistants (CNAs) were included in the pre-test and 127 CNAs in the post-test. The six intervention wards received a 4-day inho use training program. The intervention further consisted of implementation activities on the ward (e.g. stimulus preference screening, workgroup), three in-house follow-up meetings and two general meetings. Measurements on workload, perceived problems, stress reactions, job satisfaction and burnout were performed at baseline and after 18 months.

Results: A significant treatment effect in favor of the experimental group was found for time pressure, perceived problems, stress reactions and emotional exhaustion. CNAs of the experimental group also improved on their overall job satisfaction score. In particular, they were more satisfied with the quality of care and with their contact with residents.

Conclusion: The implementation of snoezelen improved the quality of the working life of dementia caregivers. 
Weert, J.C.M. van, Dulmen, A.M. van, Spreeuwenberg, P., Bensing, J.M., Ribbe, M.W. The effects of the implementation of snoezelen on the quality of working life in psychogeriatric care. International Psychogeriatrics: 2005, 17(3), 407-425

\section{INTRODUCTION}

Working in healthcare is characterized as emotionally demanding (Arts et al., 2001). Specific working conditions have been identified as stressful, such as shift work, shift rotations and lack of flexibility in working hours and time off (Chappell and Novak, 1992; Hare et al., 1988; Hoffman and Scott, 2003).

Workload is also recognized as an increasing problem among caregivers in psychogeriatric nursing homes. About 27000 patients with dementia live in Dutch nursing homes (Hoek et $a l ., 2000)$. The behavioral and psychological disturbances often accompanying dementia can be highly problematic to caregivers and can increase their workload. High workload may influence the level of stress reactions and job satisfaction negatively, possibly resulting in a negative psychological state commonly referred to as "burnout" (Blegen, 1993; Shelledy et al., 1992). Aspects such as workload, job stress, job satisfaction and burnout are associated with the concept "quality of working life," which has received increasing attention in health services research (Arts et al., 1999; 2001; Bourbonnais et al., 1998; Jansen et al., 1996).

Training and implementation of interventions for caregivers in dealing with cognitive impairment is a pro-active, inexpensive step that can be used by institutions to help alleviate the effects of stressors on caregivers (Chappell and Novak, 1992). If nurses feel that they have adequate resources to meet their patients' needs, they might be more satisfied (Shaver and Lacey, 2003).

One of the approaches that has become increasingly popular as a potential intervention on psychogeriatric wards is snoezelen, also referred to as multisensory stimulation (MSS). In the present study, snoezelen is defined as an approach, integrated into 24-hour daily care, that actively stimulates the senses of hearing, touch, vision and smell in a resident-oriented, non-threatening environment (Kok et al., 2000). The intent is to provide individualized, gentle sensory stimulation without the need for higher cognitive processes, such as memory or learning, in order to achieve or maintain a state of well-being.

Snoezelen might reduce maladaptive behaviors and increase positive behaviors of residents with dementia, but it is also used in dementia care to reduce caregivers' stress and hence to improve the quality of working life of caregivers (Chung et al., 2002; Savage, 1996).

Evidence of the expected benefits of snoezelen for staff personnel is limited. Lancioni et al. (2002) recommended the determination, in future research, of the influence of multi-sensory (snoezelen) programs on work-related outcomes of staff personnel involved in such an approach. The purpose of the current study was to investigate the effectiveness of the implementation of snoezelen, delivered by Certified Nursing Assistants (CNAs) throughout the day, on their quality of working life.

Arts et al. (2001) integrated three existing models of "quality of working life" into a new model, reflecting the relationship between workload on the one hand and psychological and physical outcomes of work on the other, with a buffer in the capacity for coping. In the current study, this model is adapted to the study purposes. The hypothesized relationship between the implementation of snoezelen, workload (organizational characteristics, job characteristics, working conditions) and psychological outcomes of work (job satisfaction, stress reactions, burnout) is shown in Figure 1. In particular, it was hypothesized that the intervention would lead to measurable, positive changes in:

- workload: the activities that someone has to carry out in a particular environment, classified in job characteristics (skill variety, learning opportunities, autonomy, having a voice) and working conditions (time pressure, role ambiguity)

- psychological outcomes of CNAs: the subjective experience of the workload, operationalized in perceived problems, stress reactions, job satisfaction and burnout. 
Weert, J.C.M. van, Dulmen, A.M. van, Spreeuwenberg, P., Bensing, J.M., Ribbe, M.W. The effects of the implementation of snoezelen on the quality of working life in psychogeriatric care. International Psychogeriatrics: 2005, 17(3), 407-425

\section{[FIGURE 1]}

\section{METHODS}

\section{Design}

A quasi-experimental pre- and post-test design was used. The study was performed at 12 psychogeriatric wards in six Dutch nursing homes, with each nursing home designating an experimental and a control ward. The six experimental wards received training in "snoezelen for caregivers" and implemented snoezelen in 24-hour care. In the six control wards, the usual care continued. The implementation period lasted 18 months per ward in the period between January 2001 and February 2003. The effectiveness of snoezelen on the quality of the working life of the CNAs was studied by using a questionnaire.

Measurements were performed at baseline and after 18 months, as this time was predicted to be the minimum needed for successful implementation.

\section{Procedures}

\section{NURSING HOMES}

Six nursing homes in different parts of the Netherlands were selected for the study out of 19 potentially eligible sites. Interviews were held with staff members to obtain information and to examine whether the nursing homes met the following inclusion criteria: (1) snoezelen had not yet been implemented in the daily care of their residents; (2) the presence of two comparable units (i.e. population of residents, composition of nursing staff, used care model, level of attention and assistance) with at least 10 CNAs that met the inclusion criteria for CNAs; (3) willingness to create the conditions to implement snoezelen

in the daily care of the experimental ward; (4) the presence of some basic, practical conditions (e.g. a comfortable residents' chair); and (5) no substantial organizational changes (e.g. removal, reorganization) during the study period.

The nursing homes signed an agreement that the control wards would refrain from snoezelen training or implementation of elements from the snoezelen care model on the wards during the study period. Control for contamination on the control wards was carried out by interviewing the head nurses 15 months after the start of the implementation on the experimental ward. These interviews revealed that on three control wards some CNAs started to apply parts of the snoezelen methodology in the daily care (e.g. music, aroma). No one integrated these parts in an individual, resident-centered approach, nor did anyone integrate these structurally. As these are considered important conditions for snoezelen to be effective, no serious contamination risk was assumed on the control wards.

Randomization took place at ward level. In four nursing homes, the two wards involved in each home were randomized by having lots drawn from a sealed container by an independent person. Two wards in the other two participating homes were assigned to the experimental group on the basis of practical considerations (e.g. the presence of a room that could be used as a snoezelroom by other disciplines such as activity therapists). This decision was taken after careful assessment of other differences between the experimental and the control ward that might prejudice treatment comparisons (e.g. population, motivation of nursing staff, working atmosphere), to rule out selection and confounding biases.

\section{SUBJECTS}

To establish the effectiveness of snoezelen, a sample size of 120 CNAs (60 treatments, 60 controls) was required (power $=0.80, \alpha=0.05, d=0.50$ ). To be eligible for the trial CNAs had to meet the following criteria: (1) be employed for at least 3 months in the nursing home; (2) be employed for at least 12 hours per week; and (3) work in rotation shifts or on day-duty. CNAs who were expected to be absent during the study period for a longer period were excluded, as were CNAs who were only working at night. CNAs who dropped out 
Weert, J.C.M. van, Dulmen, A.M. van, Spreeuwenberg, P., Bensing, J.M., Ribbe, M.W. The effects of the implementation of snoezelen on the quality of working life in psychogeriatric care. International Psychogeriatrics: 2005, 17(3), 407-425

unexpectedly were replaced by new CNAs. The new CNAs received "training on the job" from the head nurse or the "coordinator of sensory stimulation" and attended the follow-up meetings on applying the snoezelen method. They were also coached on how to bring the care into conformity with the snoezel (care) plans of the residents.

\section{Intervention}

\section{TRAINING}

The CNAs were trained in snoezelen by a qualified and experienced professional trainer of the Bernardus Center of Expertise/Fontis. In-house training included four weekly 4-hour sessions and homework. The main objectives of training were to improve caregiver knowledge and skills with regard to snoezelen and to motivate all team members to implement the new care model in 24-hour care.

Attention was paid to the residents' life history, the attitude of caregivers towards residents with dementia, observation of the residents' (sensory) preferences, and understanding of the residents' needs and practical skills with regard to sensory stimulation. Trainees received a complete caregiver reader, methodology observation forms and a certificate. In total, 59 CNAs and six head nurses attended the training program, as well as 15 other caregivers who were not formally included in the study (e.g. activity therapists or nutrition assistants).

Compliance with the training sessions was $92.5 \%$. On average, the overall assessment of the training by the caregivers on a 10-point scale was 8.4 ( $\mathrm{SD}=0.75$; range $7-10$ ).

\section{IMPLEMENTATION ON THE WARD}

After the training, the caregivers started to implement snoezelen in the 24-hour care of the residents. The CNA took a detailed history of the matched residents' life and preferences by interviewing family members. The resident was then observed during 10 weekly 1-hour sessions using the methodology acquired in the training ("stimulus preference screening"). Next, the CNAs wrote an individual snoezelen care plan in order to integrate the observation findings into the 24-hour daily care (e.g. required approach, how to wake up, whether the resident is capable of choosing own clothes, whether aroma therapy, music, perfume or make-up can be used).

\section{FOLLOW-UP AND GENERAL MEETINGS}

The caregivers were offered three in-house follow-up meetings spread over a total period of 15 months under the guidance of the same professional trainer. The aim of these supervision meetings was to support the implementation of snoezelen in daily care (e.g. practical advice, exchanging experiences, discussing problems).

In addition, there were two general meetings attended by three representatives of each nursing home (e.g. head nurses, care managers). The aim of these meetings was to support the implementation of snoezelen at the organizational level.Details about the intervention have been described elsewhere (Van Weert et al., 2004).

\section{Effects of the intervention on resident outcomes}

In a parallel study, the effects of the above-described intervention on resident outcomes were investigated. The research population consisted of 125 nursing home residents with moderate to severe dementia at pre-test (62 in the experimental group and 63 in the control group) and 128 residents at post-test (66 in the experimental group and 62 in the control group). The effectiveness of snoezelen was studied by conducting ward observations and by analyzing video recordings of morning care, using observation scales on behavior and mood of elderly people with dementia.

The results of the ward observations showed a significant treatment effect in favor of the experimental group regarding apathetic behavior, loss of decorum, rebellious behavior, aggressive behavior and depressive behavior. The results of the video-analysis showed 
Weert, J.C.M. van, Dulmen, A.M. van, Spreeuwenberg, P., Bensing, J.M., Ribbe, M.W. The effects of the implementation of snoezelen on the quality of working life in psychogeriatric care. International Psychogeriatrics: 2005, 17(3), 407-425

significant pre-/post-test changes in well-being and adaptive behavior of the residents in the experimental group. A treatment effect in favor of the experimental group was found regarding mood, happiness and contentment, enjoyment, relating well to the CNA, responding to speaking and talking with normal-length sentences. Residents of the experimental group also showed a decreased level of tearfulness/sadness, bored/inactive behavior, negativism and reluctance.

In conclusion, the results of this parallel study supported the effectiveness of snoezelen on the behavior and mood of nursing home residents with dementia. Snoezelen care particularly seemed to have a positive influence on the deterioration of disturbing and withdrawn behavior and the improvement of mood and happiness. Details about the effects of snoezelen on resident outcomes have been described elsewhere (van Weert et al., 2005). The present study elaborates on the findings by investigating the effects of snoezelen on the quality of working life of the caregivers.

\section{Outcome measures}

The various aspects of quality of working life were measured using the most reliable, valid and sensitive scales available in Dutch. Unless otherwise stated, the internal consistency of the data was sufficient to good. Details on psychometric properties are available upon request from the first author.

\section{WORKLOAD}

The questionnaire "Experience and Assessment of Work" (VBBA) by Van Veldhoven and Meijman (1994) was used for scales on job characteristics and working conditions. Four job characteristics were measured: "skill variety," "learning opportunities," "autonomy" and "having a voice."Working conditions were operationalized in "time pressure: tempo and amount of work" and "role conflict: performing tasks that are conflicting or performing tasks one prefers not doing."

\section{PSYCHOLOGICAL OUTCOMES}

Job satisfaction: Job satisfaction of the CNAs was measured by using the Maastricht Work Satisfaction Scale for Healthcare (MAS-GZ) (Landeweerd et al., 1996a; 1996b). TheMASGZ consists of seven subscales with three items, each of which are rated on a five-point scale. In addition, an overall satisfaction score was calculated including all 21 items. Four subscales were selected for the present study: satisfaction with "quality of care," "opportunities for selfactualization/ growth," "contact with colleagues" and "contact with residents." Satisfaction with "supervisor" and "possibilities for promotion" were considered to be less relevant. Satisfaction with "clarity of tasks and rules" was excluded from subgroup analysis because of the low Cronbach's $\alpha$ of 0.55 .

Perceived problems (general): To examine perceived problems of CNAs in the care for nursing home residents with dementia, the NIVEL Scale for Perceived Problems in Dementia Care (NSPP-DC) was used. This is a structured questionnaire specifically designed for assessing problems of caregivers in dementia care (Kerkstra et al., 1999). Factor analysis resulted in four subscales with an explained variance of 40.3\%: "problems caused by lack of selfconfidence/ uncertainty in the care of elderly persons with dementia," "problems caused by lack of time," "negative feelings towards behaviors of elderly persons with dementia" and "problems in the balance between emotional involvement and professional distance." Perceived problems (specific behaviors): The NIVEL Scale for Perceived Problems with Specific Behaviors of patients with dementia (NSPP-SB) was designed to measure CNAs' problems with specific behaviors often expressed by dementia patients (Kerkstra et al., 1999). The scale consists of 12 subscales: "problems with behaviors during morning care," "restless behavior," "aggression," "psychiatric symptoms," "obnoxious behavior," "behaviors during eating," "claiming behavior," "disoriented 
Weert, J.C.M. van, Dulmen, A.M. van, Spreeuwenberg, P., Bensing, J.M., Ribbe, M.W. The effects of the implementation of snoezelen on the quality of working life in psychogeriatric care. International Psychogeriatrics: 2005, 17(3), 407-425

behavior," "depressive behavior," "loss of decorum,” "social isolation” and "language disorder." A total score of the scale was calculated, including all 60 items.

Stress reactions: The short version of the GeneralHealth Questionnaire (GHQ- 12) was used to measure the CNAs' perceived stress on a range from 0 to 12 (Koeter and Ormel, 1987; Ormel et al., 1989a; 1989b). Ratings pertained to the weeks preceding the administration of the scale. Each of the 12 items were rated on one of four answering categories: “absent" (0 points), "the same as usual” (0 points), "more than usual” (1 point) or "a lot more than usual” (1 point).

Burnout: Burnout has been described as a syndrome of emotional exhaustion, depersonalization and reduced personalized accomplishment (Maslach, 1982).

The Dutch translation of the Maslach Burnout Inventory (MBI-NL) (Schaufeli and van Dierendonck, 1994; 1995; 2000; Schaufeli et al., 1993), especially developed to measure burnout in the human services sector, was used for the evaluation of burnout. The MBI-NL consists of three subscales, "emotional exhaustion," "depersonalization" and "personal accomplishment," with a total of 20 items. Because of the low Cronbach's $\alpha$ of the depersonalization subscale $(\alpha=0.54)$, which is in support of earlier findings on the internal consistency of this subscale, the subscale was excluded from the analysis (Arts et al., 2001; Jansen et al., 1996; Schaufeli et al., 1993; 1994).

\section{DATA MANAGEMENT AND ANALYSIS}

Data management: All questionnaires were reviewed immediately after they were received. Uncompleted questionnaires were sent back to the CNA. The remaining missing values on items that were part of a (sub-)scale were substituted according to the "mean value of valid subtests principle": the missing value was replaced by the mean value calculated from the valid item scores of the (sub-) scale obtained for the same case at the same time point (Schrijnemaekers et al., 2003). This replacement strategy was only used if $25 \%$ or less of the items of the (sub-)scale hadmissing values. If more than $25 \%$ of the items hadmissing values, the (sub-)scale of that case was excluded from analysis ( $n$ in tables represent the number of questionnaires that could be analyzed).

Data analysis: Descriptive statistics were obtained on the demographic characteristics of subjects pre- and post-test and in the experimental and control groups. Differences in these variables were examined using $\chi^{2}$-tests or $t$-tests. $t$-tests were also used to examine differences between completers and noncompleters (i.e. dropouts and newly included CNAs).

As dropouts were substituted by new CNAs, multilevel analysis, carried out with MLwiNsoftware, was used for analyzing the data (Bryk and Raudenbusch, 1992; Goldstein, 1995).Amodel ofmultilevel analysis of repeated measurements was chosen that takes into account all available data in an adequate way: the paired data of completers as well as the unpaired data of dropouts and newly included CNAs. The multilevel analysis also took account of dependencies among measurements, caused by the hierarchical structure of the data (measurement occasions nested within caregivers, who are nested within wards). We distinguished three levels of analysis: (1) measurement, (2) CNA and (3) ward. By including the ward level, the similarity within wards could be taken into account, meaning that the "CNA nested within ward" effect and its interactions are accounted for. Change scores were computed to compare the rate of change across the experimental and the control group on each measure from pre- to post-test. The mean pre-test/post-test differences in the experimental group were tested against the mean pretest/posttest differences in the control group. Additional adjusted analysis were conducted in which the following characteristics were added as covariates: age, sex, years of working experience, years of employment on the present ward, and hours of employment per week. 
Weert, J.C.M. van, Dulmen, A.M. van, Spreeuwenberg, P., Bensing, J.M., Ribbe, M.W. The effects of the implementation of snoezelen on the quality of working life in psychogeriatric care. International Psychogeriatrics: 2005, 17(3), 407-425

\section{RESULTS}

\section{Response}

Figure 2 presents the response and dropouts over time per group (experimental or control). One hundred and thirty-four CNAs were selected to participate in the pre-test, five of whom did not respond (one refused to complete the questionnaire, one changed her job, the request to participate sent to one was lost in the mail, two did not respond for unclear reasons). Thirty-seven CNAs were lost to follow-up (19 in the experimental group and 18 in the control group). They were substituted by new CNAs. At post-test, only one person did not respond (due to illness). In total, 129 questionnaires from CNAs were analyzed for the pretest (64 in the experimental group and 65 in the control group) and 127 for the post-test (64 in the experimental group and 63 in the control group). The mean number of questionnaires analyzed per ward was 10.7 for the experimental group at pre-test (range 9-12), 10.8 for the control group at pre-test (range 7-14), 10.7 for the experimental group at post-test (range 714) and 10.5 for the control group at post-test (range 10-11).

\section{[FIGURE 2]}

Interviews were held with the head nurses of the experimental wards to discover the reasons why dropouts left their job and to find out whether their leave was connected with the implementation of the new caremodel. EightCNAs left their jobs to be employed in another care setting such as home care, mainly for practical reasons (e.g. no shifts, physically less demanding). Four CNAs were transferred to another ward in the same nursing home. The remainder changed for other reasons. According to the head nurses, the implementation of snoezelen played a role in the decision to change of five CNAs (three leaving to another ward in the same nursing home, one to another care setting, one leaving after illness).

In addition, subgroup analyses were performed to control for differences between completers and noncompleters (dropouts and newly included CNAs replacing the dropouts). In the pre-test, there were no significant differences between completers and dropouts with regard to background characteristics and outcome measures for the experimental or the control group. In the posttest, completers of both the experimental and the control groups were employed significantly longer on the ward than newly included CNAs, as was expected (experimental: $4.8 v s .1 .9$ years, $p=0.009$; control: $4.9 v s .1 .8$ years, $p=0.004$ ).

In the experimental group, completers hadmore experience than newly included CNAs (9.4 $v s .4 .5$ years, $p=0.01)$. There were no other differences either, in background characteristics or in outcome measures, between completers and dropouts, respectively, and newly included CNAs in the experimental and the control groups.

\section{Background characteristics}

Table 1 summarizes the demographic characteristics of CNAs in the pre-test and the posttest. The table shows that the background characteristics of the experimental and control groups were to a large extent comparable. There were no significant differences between the experimental group and the control group at pre-test and at post-test, nor between measures within the experimental group or the control group.

\section{[TABLE 1]}

\section{Outcomes}

\section{WORKLOAD}

Table 2 shows the adjusted estimated means (95\% confidence interval) and the change scores from the experimental group in comparison with the control group on all variables regarding workload. On all measures in this table, positive change scores indicate a change in favor of the experimental group. 
Weert, J.C.M. van, Dulmen, A.M. van, Spreeuwenberg, P., Bensing, J.M., Ribbe, M.W. The effects of the implementation of snoezelen on the quality of working life in psychogeriatric care. International Psychogeriatrics: 2005, 17(3), 407-425

A significant treatment effect was obtained for "having a voice," "time pressure" and "role conflict." "Time pressure" decreased significantly in the experimental group. The effects of "having a voice" and "role conflict" were obtained because, in the opinion of the control group, "having a voice" and "role conflicts" had significantly, negatively changed in comparison with the pre-test.

\section{[TABLE 2]}

\section{PSYCHOLOGICAL OUTCOMES}

The effects of snoezelen on perceived problems of CNAs, part of the psychological workrelated outcomes, are presented in Table 3 . In this table, positive change scores indicate a change in favor of the experimental group.

The scores on NSPP-DC showed a significant treatment effect in favor of the experimental group for the subscales "lack of self-confidence and uncertainty in care" and problems caused by "lack of time." Within the experimental group there was also a significant change from pre- to post-test on these subscales, as well as on the subscale "negative feelings towards behaviors of elderly persons with dementia." The latter, however, did not result in a significant treatment effect.

The experimental group also showed a significant, positive change in the total score of perceived problems with specific behavior of elderly persons with dementia (NSPP-SP). With regard to the 12 subscales of this scale, a significant treatment effect was found for depressive behavior (change score 2.47; $p<0.001$ ), loss of decorum (change score 2.08; $p<0.05$ ) and restless behavior (change score 1.79; $p<0.05$ ) (not presented in table).

Table 4 presents the adjusted estimated means and change scores of the experimental group in comparison with the control group on stress reactions, job satisfaction and burnout, all part of the psychological work-related outcomes.

On measures representing job satisfaction and the burnout subscale "personal accomplishment," a negative change score indicates a change in favor of the experimental group. On the other measurements, a positive change score is in favor of the experimental group.

\section{[TABLE 3]}

\section{[TABLE 4]}

There was a significant effect on stress reactions and emotional exhaustion in favor of the experimental group. Significant improvements in favor of the experimental group were also found in satisfaction with the quality of care, satisfaction with contact with residents and total satisfaction. For these subscales, there was a significant, positive change from pre-test to post-test in the experimental group, as well as a significant treatment effect. Satisfaction with growth (self-actualization) showed a significant pre-test/post-test change as a result of increased satisfaction $(p<0.1)$ in the experimental group and decreased satisfaction $(p<0.05)$ in the control group.

\section{DISCUSSION}

The results of this study support the effectiveness of snoezelen in improving the quality of working life of CNAs in dementia care. With regard to workload, time pressure decreased from pre- to post-test in the experimental group, although the number of staff members had not been increased. CNAs working at wards that implemented snoezelen in 24-hour daily care showed fewer stress reactions and less emotional exhaustion than those applying usual care. The experimental group was more satisfied with their contact with residents and with 
Weert, J.C.M. van, Dulmen, A.M. van, Spreeuwenberg, P., Bensing, J.M., Ribbe, M.W. The effects of the implementation of snoezelen on the quality of working life in psychogeriatric care. International Psychogeriatrics: 2005, 17(3), 407-425

the quality of care than the control group. Total satisfaction and satisfaction with growth also showed a treatment effect in favor of the experimental group.

Moreover, the experimental group noted fewer problems caused by lack of time and by uncertainty. They also perceived fewer problems with specific behaviors of residents, especially with depressive behavior, loss of decorum and restless behavior. In a parallel study investigating the effects of snoezelen

on the behavior of nursing home residents with dementia, positive effects were found, among others, on depression, apathy and loss of decorum (van Weert et al., 2005). These behaviors seem to be sensitive to the snoezelen

approach. In the present study, CNAs also reported that they could better deal with these behaviors after the implementation of snoezelen. The results are in conformity with the subjective experiences of participating CNAs, evaluated during follow-up meetings and interviews with head nurses and project leaders. CNAs mentioned that, on the one hand, withdrawn residents became more responsive and, on the other hand, residents with disturbing behavior became quieter. They reported that the implementation of snoezelen resulted in a more relaxed working style, but that they were still able to get the work finished, for example because they were less hindered by disturbing behavior of residents (van Weert et al., 2004). Factors relating to workload, residents' outcomes and psychological caregivers' outcomes seem to reinforce each other in circular processes, which indicates that the hypothesized research model should be extended with residents' outcomes. How these factors interact precisely with each other has to be determined in future research.

The results are partly supportive of recent literature. Hoffman and Scott (2003) found that nurses experienced greater professional fulfillment and career satisfaction when strategies are implemented that promote autonomous practice environments, recognize professional status and provide financial incentives.

Snoezelen fits best in a "staff-centered work environment," meeting the needs of autonomy and professional recognition (Kitwood, 1997; van Weert et al., 2004), but not an increased salary. According to Shelledy et al. (1992), satisfaction with pay cannot only be predicted by the actual salary but also by factors such as job independence, job stress and organizational climate.

Institutions should therefore be looking for ways to lighten the demands at work and make the work more interesting (Chappell and Novak, 1992). The implementation of snoezelen seems to be an appropriate tool to reach these goals.

This gives rise to the question whether nursing homes have the financial means to implement an innovative care model such as snoezelen. In the present study, the snoezelen environment was broadened to a multidimensional concept, that is, a total package that has to be applied throughout the day by all caregivers involved, including a resident-oriented attitude and multisensory stimulation.

The latter does not have to be a "high-tech" package. A special snoezelen room can have additional value, but is not definitely required. Simple attributes in the environment of the residents, combined with some creativity of caregivers, are sufficient. This means that investments in snoezelen equipment might vary from around $200 €$ (only simple attributes) to $25000 €$ (e.g. for a wellequipped snoezelen room) or even more (e.g. for a snoezelen bathroom). An investment that certainly has to be made is in training in snoezelen, preferably for all CNAs, but also for supervisors and other disciplines, such as activity therapists. Training will cost around $365 €$ per trainee or $3000 €$ per inhouse course for 15 trainees (excluding travel allowance). Training costs have to be estimated structurally to educate new team members. Moreover, it is recommended to rate costs for supervision meetings to support the implementation.

\section{Limitations}

A few methodological considerations require attention. First, although the multilevel model takes into account the data of completers (included in pre-test and post-test) as well as non- 
Weert, J.C.M. van, Dulmen, A.M. van, Spreeuwenberg, P., Bensing, J.M., Ribbe, M.W. The effects of the implementation of snoezelen on the quality of working life in psychogeriatric care. International Psychogeriatrics: 2005, 17(3), 407-425

completers (included in pre-test or post-test), the results might be biased. The loss to followup due to structural dropout was similar for the two study groups. There were not sufficient differences between completers and dropouts or between completers and newly included CNAs with regard to background characteristics and outcome measures. Furthermore, post hoc subgroup analyses were carried out on the variables that showed significant changes. The results showed no contradictions between the subgroup of completers and the total group. Therefore, no large bias of the results by dropouts and newly included CNAs is assumed.

Second, the implementation of snoezelen on the experimental wards brought new enthusiasm to staff members. This might be subsumed under the term "Hawthorne effect" because the intervention was compared to "real-life" daily dementia care given by the control group. Caregivers who have the opportunity to follow a training course may have improved job satisfaction regardless of the content of the training. However, if the Hawthorne effect were to explain all the results, this effect would have occurred in previous studies that used a "usual care" control group too (e.g. in Schrijnemaekers et al., 2003). Moreover, our results were not marginal but were convincing and in conformity with the findings of parallel studies. Therefore, the Hawthorne effect is not assumed to explain all the effects in the present study.

Third, the outcome measures could not be blinded, which may lead to an overestimation of effects. Therefore, complete scales were included in the questionnaire, although we did not expect effects on all subscales. The effects found were in conformity with the effects assumed.

\section{CONCLUSION AND RECOMMENDATIONS}

The results suggest that the implementation of snoezelen adds to the quality of working life of CNAs in psychogeriatric care. To confirm our findings, the study should be repeated, preferably by exposing a second control group to a treatment that is equivalent (e.g. education and training) to the snoezelen treatment. In the meantime, the implementation of this care model on psychogeriatric wards of nursing homes with patients with moderate to severe dementia seems to be promising. In future studies, research is also recommended onwhether decreased job stress, increased job satisfaction and decreased emotional exhaustion do indeed result in physical outcomes, such as decreased sick-leave.

\section{CONFLICT OF INTEREST DECLARATION}

This research project was financed by ZonMW; Netherlands Organization for Health Research and Development, research program "Elderly Care," Foundation Central Fund RVVZ and the Province of Zeeland. Barry Emons gave the participating experimental wards a discount on snoezel materials. There is no financial relationship between any author and any organization with a vested interest in the conduct and reporting of the study.

\section{DESCRIPTION OF AUTHORS' ROLES}

The results of this study were part of the thesis of the first author, J. van Weert, who collected the data, conducted the statistical analysis and wrote the paper. S. van Dulmen was the supervisor and copromoter of the first author. P. Spreeuwenberg was responsible for carrying out the multilevel analysis.

J. Bensing submitted the application and was the first promoter of the first author. M. Ribbe provided additional knowledge from a nursing home medical background and was the second promoter of the first author. 
Weert, J.C.M. van, Dulmen, A.M. van, Spreeuwenberg, P., Bensing, J.M., Ribbe, M.W. The effects of the implementation of snoezelen on the quality of working life in psychogeriatric care. International Psychogeriatrics: 2005, 17(3), 407-425

\section{ACKNOWLEDGMENTS}

We thank the residents, their legal guardians, the CNAs and the staff for their commitment to our study, and the Bernardus Center of Expertise/Fontis, and in particular Jan Peter (teacher) for organizing and performing the intervention in our study and supporting the implementation on the wards.

\section{REFERENCES}

Arts, S. E. J., Kerkstra, A., van der Zee, J. and Huijer Abu-Saad, H. (1999). Workload, capacity for coping and psychological outcomes amongst home helps in the Netherlands. Health and Social Care in the Community, 7, 79-90.

Arts, S. E. J., Kerkstra, A., van der Zee, J. and Huijer Abu-Saad, H. (2001). Quality of working life and workload in home help services. A review of the literature and a proposal for a research model. Scandinavian Journal of Caring Sciences, 15, 12-24.

Blegen, M. A. (1993) Nurses' job satisfaction: a meta-analysis of related variables. Nursing Research, 42, 36-41.

Bourbonnais, R., Comeau, M., Vezina, M. and Dion, G. (1998). Job strain, psychological distress, and burnout in nurses. American Journal of Industrial Medicine, 34, 20-28.

Bryk, A. S. and Raudenbusch, S. W. (1992). Hierarchical Linear Models: Applications and Data

Management Methods. Newbury Park: Sage Publications.

Chappell, N. L. and Novak, M. (1992). The role of support in alleviating stress among nursing assistants. The Gerontologist, 32, 351-359.

Chung, J. C. C., Lai, C. K. Y., Chung, P. M. B. and French, H. P. (2002). Snoezelen for dementia (Cochrane Review). In The Cochrane Library, Issue 4. Oxford: Update Software. Goldstein, H. (1995). Multilevel Statistical Models. New York: Halsted Press.

Hare, J., Pratt, C. C. and Andrews, D. (1988). Predictors of burnout in professional and paraprofessional nurses working in hospitals and nursing homes. International Journal of Nursing Studies, 25, 105-115.

Hoek, J. P., Pennix, B. W. J. H., Ligthart, G. J. and Ribbe, M. W. (2000). Health care for older persons, a country profile: the Netherlands. Journal of the American Geriatrics Society, 48, 214-217.

Hoffman, A. J. and Scott, L. D. (2003). Role stress and career satisfaction among registered nurses by work shift patterns. Journal of Nursing Administration, 33, 337-342.

Jansen, P. G. M., Kerkstra, A., Abu-Saad, H. H. and van der Zee, J. (1996). The effect of job characteristics and individual characteristics on job satisfaction and burnout in community nursing. International Journal of Nursing Studies, 33, 407-421.

Kerkstra, A., van Bilsen, P. and Otten, D. D. (1999). Omgaan met Dementerende Bewoners in

het Verpleeghuis [Dealing with nursing home residents with dementia]. Utrecht: NIVEL.

Kitwood, T. (1997). Dementia Reconsidered: the Person Comes First. Buckingham: Open University Press.

Koeter, M. W. J. andOrmel, J. (1987). General Health Questionnaire. Nederlandse Bewerking.

Handleiding [General Health Questionnaire. Dutch version. Manual]. Lisse: Swets.

Kok, W., Peter, J. and Choufour, J. (2000). Snoezelen. Amsterdam: Bernardus Expertisecentrum/Fontis.

Lancioni, G. E., Cuvo, A. J. andO'Reilly, M. F. (2002). Snoezelen: an overview of research with people with developmental disabilities and dementia. Disability and Rehabilitation, 24, 175-184.

Landeweerd, J. A., Boumans, N. P. G. and Nissen, J. M. F. (1996a). Arbeidsvoldoening bij verplegenden en verzorgenden. De Maastrichtse Arbeidssatisfactieschaal voor de Gezondheidszorg [Job satisfaction of nurses and nursing assistants. The Maastricht Work Satisfaction Scale for Healthcare]. In C. C. van Beek, T. C. van Dorsten and G. J. Stam (Eds.) Handboek Verpleegkundige Innovatie. Houten: Bohn Stafleu.

Landeweerd, J. A., Boumans, N. P. G. and Nissen, J. M. F. (1996b). Bedrijfsgezondheidszorg 
Weert, J.C.M. van, Dulmen, A.M. van, Spreeuwenberg, P., Bensing, J.M., Ribbe, M.W. The effects of the implementation of snoezelen on the quality of working life in psychogeriatric care. International Psychogeriatrics: 2005, 17(3), 407-425

Studies nr. 11. De Maastrichtse Arbeidssatisfactieschaal voor de Gezondheidszorg (MAS-

GZ) [the Maastricht Work Satisfaction Scale for Healthcare]. Maastricht: Universiteit Maastricht.

Maslach, C. (1982). Burnout: the Cost of Caring. Englewood Cliffs: Prentice Hall.

Ormel, J., Koeter, M. W., van den Brink, W. and Giel, R. (1989a). Concurrent validity of

GHQ-28 and PSE as measure of change. Psychological Medicine, 19, 1007-1013.

Ormel, J., Koeter, M. W. and van den Brink, W. (1989b). Measuring change with the General Health Questionnaire (GHQ). The problem of retest effects. Social Psychiatry and Psychiatric Epidemiology, 24, 227-232.

Savage, P. (1996). Snoezelen for confused people. Some concerns. Elderly Care, 8, 20-21.

Schaufeli, W. and van Dierendonck, D. (1994). Burnout, een begrip gemeten. De Nederlandse versie van de Maslach Burnout Inventory (MBI-NL). [Burnout, the measurement of a concept: the Dutch version of the Maslach Burnout Inventory (MBI-NL)]. Gedrag en Gezondheid: Tijdschrift voor Psychologie en Gezondheid, 22, 153-172.

Schaufeli, W. B. and van Dierendonck, D. (1995). A cautionary note about the cross-national and clinical validity of cut-off points for the Maslach Burnout Inventory. Psychological Reports, 76, 1083-1090.

Schaufeli, W. and van Dierendonck, D. (2000). UBOS.Utrechtse Burnout Schaal. Handleiding

[MBI-NL. Dutch version of the Maslach Burnout Inventory. Manual]. Lisse: Swets.

Schaufeli, W. B., Maslach, T. and Marek, T. (Eds.) (1993). Professional Burnout: Recent Developments in Theory and Research. Washington DC: Taylor \& Francis.

Schrijnemaekers, V. J. J. (2001). The Effectiveness of Emotion-oriented Care in Homes for the

Elderly. Dissertation. Maastricht: VJJ Schrijnemaekers.

Schrijnemaekers, V. J. J. et al. (2003). Effects of emotion-oriented care on work-related outcomes of professional caregivers in homes for elderly persons. Journal of Gerontology B:

Social Sciences, 58B, S50-S57.

Shaver, K. H. and Lacey, L. M. (2003). Job and career satisfaction among staff nurses: effects of job setting and environment. Journal of Nursing Administration, 33, 166-172. Shelledy, D. C., Mikles, S. P., May, D. F. and Youtsey, J. W. (1992). Analysis of job satisfaction, burnout, and intent of respiratory care practitioners to leave the field or the job. Respiratory Care, 37, 46-60.

van Veldhoven, M. and Meijman, T. (1994). Het Meten van Psychosociale Arbeidsbelasting [The measurement of psychosocial workload]. Amsterdam: NIA.

van Weert, J. C. M., Kerkstra, A., Dulmen, A. M., Bensing, J. M. and Ribbe, M. W. (2004). The implementation of snoezelen in psychogeriatric care: an evaluation through the eyes of caregivers. International Journal of Nursing Studies, 41, 397-409.

van Weert, J. C. M., van Dulmen, A. M., Spreeuwenberg, P. M. M., Ribbe, M. W. and Bensing, J. M. (2005). Behavioral and mood effects of snoezelen, integrated in 24-hour dementia care. Journal of the American Geriatrics Society, 53, 24-33. 
Weert, J.C.M. van, Dulmen, A.M. van, Spreeuwenberg, P., Bensing, J.M., Ribbe, M.W. The effects of the implementation of snoezelen on the quality of working life in psychogeriatric care. International Psychogeriatrics: 2005, 17(3), 407-425

FIGURES AND TABLES

Figure 1. Research model.

\begin{tabular}{|c|c|c|}
\hline Intervention & Workload & $\begin{array}{l}\text { Psychological } \\
\text { outcomes }\end{array}$ \\
\hline $\begin{array}{l}\text { Implementation of } \\
\text { snoezelen in 24-hour } \\
\text { daily care }\end{array}$ & $\begin{array}{l}\text { Job characteristics } \\
\text { - } \quad \text { skill variety } \\
\text { - } \text { learning } \\
\text { opportunities } \\
\text { - } \text { autonomy } \\
\text { - having a voice } \\
\text { Working conditions } \\
\text { - } \text { time pressure } \\
\text { - } \text { role conflict }\end{array}$ & $\begin{array}{l}\text { Perceived problems } \\
\text { - with general } \\
\text { dementia care } \\
\text { with specific } \\
\text { behaviors of } \\
\text { elderly persons } \\
\text { with dementia } \\
\text { Stress reactions } \\
\text { Job satisfaction } \\
\text { Burnout }\end{array}$ \\
\hline
\end{tabular}

Figure 2. Flow chart of the trial.

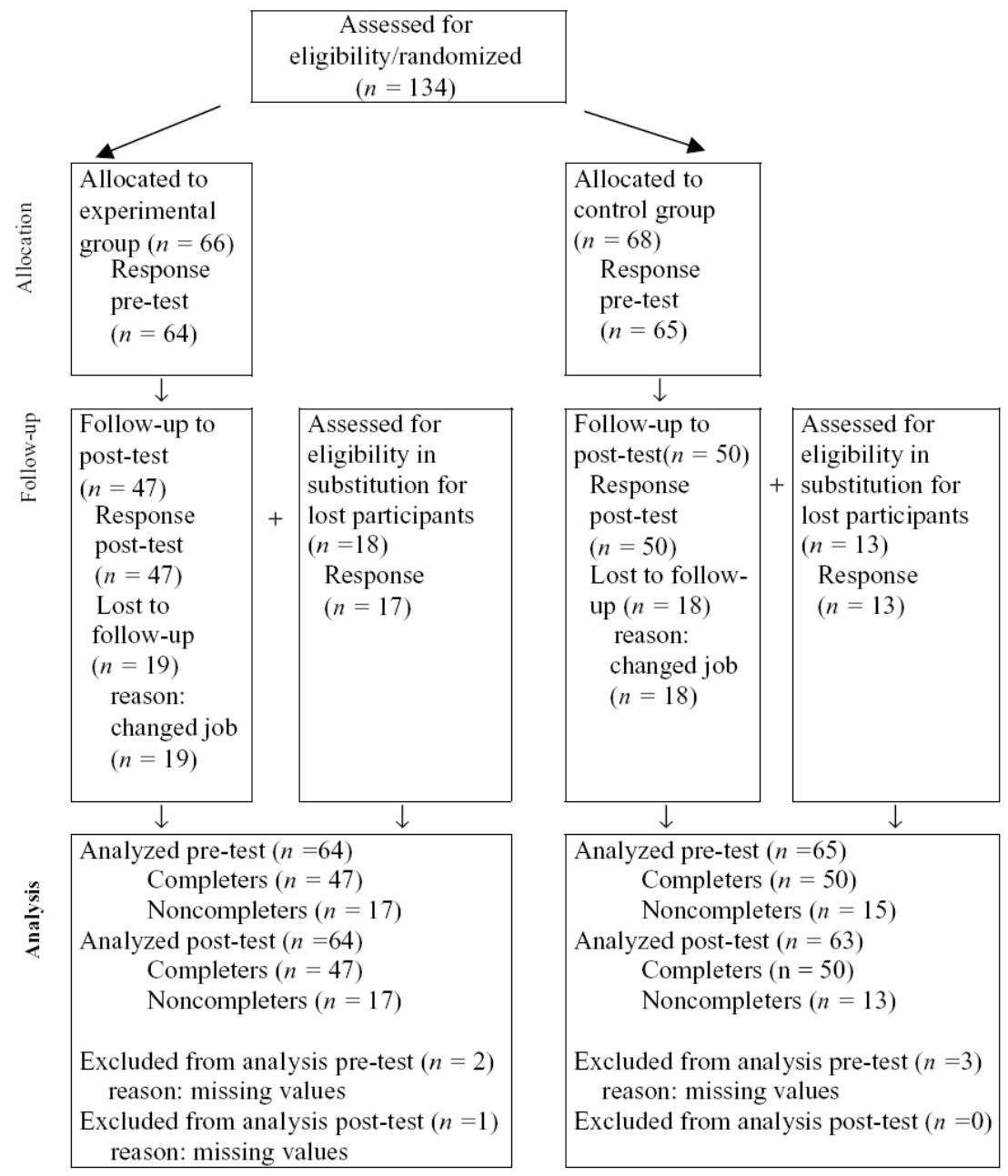


Table 1. Background characteristics of participating CNAS

\begin{tabular}{|c|c|c|c|c|c|c|c|c|}
\hline \multirow{3}{*}{$\begin{array}{l}\text { CHARACTERISTICS OF CNAs } \\
\text { Gender: female }(n,(\%))\end{array}$} & \multicolumn{4}{|c|}{ EXPERIMENTAL GROUP } & \multicolumn{4}{|c|}{ CONTROL GROUP } \\
\hline & \multicolumn{2}{|c|}{$\begin{array}{c}\text { PRE-TEST } \\
(n=64)\end{array}$} & \multicolumn{2}{|c|}{$\begin{array}{c}\text { POST-TEST } \\
(n=64)\end{array}$} & \multicolumn{2}{|c|}{$\begin{array}{c}\text { PRE-TEST } \\
(n=65)\end{array}$} & \multicolumn{2}{|c|}{$\begin{array}{c}\text { POST-TEST } \\
(n=63)\end{array}$} \\
\hline & 59 & $(92.2)$ & 58 & $(90.6)$ & 60 & $(92.3)$ & 59 & $(93.7)$ \\
\hline Age (years, (SD)) & 36.6 & $(10.9)$ & 36.3 & $(10.9)$ & 33.2 & $(9.5)$ & 36.3 & $(10.2)$ \\
\hline $\begin{array}{l}\text { Hours of employment per } \\
\text { week (mean hours, (SD)) }\end{array}$ & 29.3 & $(10.9)$ & 27.9 & $(7.5)$ & 29.0 & $(7.4)$ & 28.7 & $(7.6)$ \\
\hline $\begin{array}{l}\text { Psychogeriatric experience } \\
\text { (mean years, (SD)) }\end{array}$ & 7.8 & $(6.4)$ & 8.1 & $(6.8)$ & 7.4 & (6.3) & 9.0 & $(8.2)$ \\
\hline $\begin{array}{l}\text { Employed on this ward } \\
\text { (mean years, (SD)) }\end{array}$ & 3.6 & $(4.0)$ & 4.0 & $(3.9)$ & 3.4 & (3.7) & 4.3 & $(3.5)$ \\
\hline \multicolumn{9}{|l|}{ Position $(n,(\%))$} \\
\hline Team leader & 5 & (7.8) & 4 & (6.3) & 7 & $(10.8)$ & 5 & $(7.9)$ \\
\hline Nursing assistant & 52 & (81.3) & 53 & $(82.8)$ & 48 & (73.8) & 50 & $(79.4)$ \\
\hline $\begin{array}{l}\text { Other (ward assistant, } \\
\text { geriatric helper) }\end{array}$ & 7 & $(10.9)$ & 7 & $(10.9)$ & 10 & $(15.4)$ & 8 & (12.8) \\
\hline
\end{tabular}

To test the differences in background characteristics, $t$-tests and $x^{2}$ analysis were used. There were no significant differences in background characteristics. 
Table 2. Change in outcome measures regarding workload (multilevel analysis)

\begin{tabular}{|c|c|c|c|c|c|c|c|c|c|c|c|c|c|}
\hline \multirow[b]{3}{*}{ OUTCOME MEASURES } & \multirow[b]{3}{*}{$n^{6}$} & \multicolumn{5}{|c|}{ EXPERIMENTAL GROUP } & \multicolumn{5}{|c|}{ CONTROL GROUP } & \multirow{3}{*}{$\begin{array}{l}\text { CHANGE } \\
\text { SCORE }^{b}\end{array}$} & \multirow[b]{3}{*}{$\chi^{2}(1)$} \\
\hline & & \multicolumn{2}{|c|}{ PRE-TEST } & \multicolumn{2}{|c|}{ POST-TEST } & \multirow[b]{2}{*}{ CHANGE } & \multicolumn{2}{|c|}{ PRE-TEST } & \multicolumn{2}{|c|}{ POST-TEST } & \multirow[b]{2}{*}{ CHANGE } & & \\
\hline & & $\mathrm{M}$ & $(\mathrm{SE})$ & $M$ & (SE) & & $\mathrm{M}$ & $(\mathrm{sE})$ & $\mathrm{M}$ & (SE) & & & \\
\hline \multicolumn{14}{|l|}{ Job characteristics (VBBA) ${ }^{a}$} \\
\hline Skill variety $(\underline{0}-18)$ & 255 & 7.09 & $(0.5)$ & 6.80 & $(0.4)$ & 0.29 & 7.29 & $(0.5)$ & 7.88 & $(0.4)$ & -0.59 & 0.89 & 2.24 \\
\hline Learning opportunities ( $(0-12)$ & 255 & 5.52 & $(0.3)$ & 5.15 & $(0.3)$ & 0.37 & 5.63 & $(0.3)$ & 5.80 & $(0.3)$ & -0.17 & 0.54 & 1.45 \\
\hline Autonomy (ㅇ-33) & 255 & 15.12 & $(0.5)$ & 14.49 & $(0.6)$ & 0.64 & 15.22 & $(0.5)$ & 16.15 & $(0.6)$ & -0.93 & 1.57 & 3.62 \\
\hline Having a voice $(\underline{0}-24)$ & 255 & 10.71 & $(0.8)$ & 9.96 & $(0.8)$ & 0.75 & 9.37 & $(0.8)$ & 11.16 & $(0.8)$ & $-1.79^{* * *}$ & $2.54^{* * *}$ & 10.88 \\
\hline \multicolumn{14}{|l|}{ Working conditions (VBBA) ${ }^{a}$} \\
\hline Time pressure $(\underline{0}-33)$ & 255 & 15.67 & $(1.0)$ & 13.84 & $(1.0)$ & $1.84^{*+*}$ & 15.55 & $(1.0)$ & 15.82 & $(1.0)$ & -0.26 & $2.10^{* *}$ & 7.52 \\
\hline Role conflict $(\underline{0-1} 8)$ & 255 & 3.68 & $(0.2)$ & 3.48 & $(0.3)$ & 0.19 & 3.21 & $(0.2)$ & 3.90 & $(0.3)$ & $-0.69^{*}$ & $0.89^{*}$ & 5.74 \\
\hline
\end{tabular}

${ }^{*} p<005,{ }^{* *} p<001,{ }^{* * *} p<0001$.

a The underlined scores indicate the most favorable score for the scale.

bScores in italics indicate a significant change in favor of the experimental group, meaning that the pre-/post-change in the experimental group is significantly different from the pre-/post-change in the control group.

'Number of questionnaires included in the analysis $(N=256)$.

VBBA $=$ Experience and Assessment of Work Questionnaire.

$\chi^{2}(1)=$ chi square (1 degree of freedom). 
Table 3. Change in outcome measures regarding perceived problems of CNAs (multilevel analysis)

\begin{tabular}{|c|c|c|c|c|c|c|c|c|c|c|c|c|c|}
\hline \multirow[b]{3}{*}{ OUTCOME MEASURES } & \multirow[b]{3}{*}{$n^{\mathrm{c}}$} & \multicolumn{5}{|c|}{ EXPERIMENTAL GROUP } & \multicolumn{5}{|c|}{ CONTROL GROUP } & \multirow{3}{*}{$\begin{array}{l}\text { CHANGE } \\
\text { SCORE }^{\mathrm{b}}\end{array}$} & \multirow[b]{3}{*}{$\chi^{2}(1)$} \\
\hline & & \multicolumn{2}{|c|}{ PRE-TEST } & \multicolumn{2}{|c|}{ POST-TEST } & \multirow[b]{2}{*}{ CHANGE } & \multicolumn{2}{|c|}{ PRE-TEST } & \multicolumn{2}{|c|}{ POST-TEST } & \multirow[b]{2}{*}{ CHANGE } & & \\
\hline & & $M$ & $(\mathrm{SE})$ & $\mathrm{M}$ & (SE) & & $M$ & $(\mathrm{SE})$ & $M$ & (SE) & & & \\
\hline \multicolumn{14}{|l|}{ Perceived problems (NSPP_DC)a } \\
\hline $\begin{array}{l}\text { Lack of self-confidence/ } \\
\text { uncertainty }(\underline{0}-40)\end{array}$ & 254 & 10.61 & $(0.6)$ & 8.81 & $(0.6)$ & $1.80^{*+*}$ & 9.93 & $(0.6)$ & 10.59 & $(0.6)$ & -0.66 & $2.46^{+*+*}$ & 13.47 \\
\hline Lack of time $(\underline{0-24)}$ & 252 & 13.36 & $(0.8)$ & 11.78 & $(0.8)$ & $1.58^{*}$ & 11.96 & $(0.8)$ & 13.21 & $(0.8)$ & -1.24 & $2.82^{* *}$ & 9.41 \\
\hline Negative feelings $(\underline{0}-32)$ & 254 & 7.79 & $(0.6)$ & 6.40 & $(0.5)$ & $1.39^{*}$ & 8.74 & $(0.6)$ & 8.24 & $(0.5)$ & 0.49 & 0.89 & 1.38 \\
\hline Balance $(\underline{0}-24)$ & 253 & 6.73 & $(0.7)$ & 6.41 & $(0.6)$ & 0.32 & 6.64 & $(0.7)$ & 6.51 & $(0.6)$ & 0.13 & 0.19 & 0.08 \\
\hline \multicolumn{14}{|l|}{ Perceived problems (NSPP_SB)a } \\
\hline $\begin{array}{l}\text { Total problems with residents' } \\
\text { behavior }(\underline{0}-240)\end{array}$ & 235 & 94.17 & $(4.7)$ & 84.84 & $(4.9)$ & $9.33^{*}$ & 92.44 & $(4.6)$ & 97.92 & $(4.8)$ & -5.49 & $14.82^{* *}$ & 7.08 \\
\hline
\end{tabular}

$* p<005, * p<001, * * p<0001$.

"The underlined scores indicate the most favorable score for the scale.

${ }^{b}$ Scores in italics indicate a significant change in favor of the experimental group, meaning that the pre-/post change in the experimental group is significantly different from the pre-ipost change in the control group.

'Number of questionnaires included in the analysis $(N=256)$.

NSPP-DC $=$ NIVEL Scale for Perceived Problems in Dementia Care.

NSPP-SB = NIVEL Scale for Perceived Problems with Specific Behaviors of patients with dementia.

$\chi^{2}(1)=$ chi square (1 degree of freodom) 
Table 4. Change in outcome measures regarding stress reactions, job satisfaction and burnout (multilevel analysis)

\begin{tabular}{|c|c|c|c|c|c|c|c|c|c|c|c|c|c|}
\hline \multirow[b]{3}{*}{ OUTCOME MEASURES } & \multirow[b]{3}{*}{$n^{\circ}$} & \multicolumn{5}{|c|}{ EXPERIMENTAL GROUP } & \multicolumn{5}{|c|}{ CONTROL GROUP } & \multirow{3}{*}{$\begin{array}{l}\text { CHANGE } \\
\text { SCORE }^{b}\end{array}$} & \multirow[b]{3}{*}{$\chi^{2}(1)$} \\
\hline & & \multicolumn{2}{|c|}{ PRE-TEST } & \multicolumn{2}{|c|}{ POST-TEST } & \multirow[b]{2}{*}{ CHANGE } & \multicolumn{2}{|c|}{ PRE-TEST } & \multicolumn{2}{|c|}{ POST-TEST } & \multirow[b]{2}{*}{ CHANGE } & & \\
\hline & & $M$ & $(\mathrm{sE})$ & $\mathrm{M}$ & $(\mathrm{sE})$ & & $\mathrm{M}$ & $(\mathrm{SE})$ & $\mathrm{M}$ & (SE) & & & \\
\hline \multicolumn{14}{|l|}{ Stress reactions $(\mathrm{GHQ})(\underline{0}-12)^{\mathrm{a}}$} \\
\hline GHQ-12 score & 256 & 1.46 & $(0.4)$ & 0.77 & $(0.4)$ & $0.69^{*}$ & 1.24 & $(0.4)$ & 1.93 & $(0.4)$ & $-0.69^{*}$ & $1.37^{*}$ & 8.60 \\
\hline \multicolumn{14}{|l|}{ Job satisfaction (MAS-GZ) $(0-\underline{12})^{a}$} \\
\hline Supervisor & 253 & 7.08 & $(0.5)$ & 7.65 & $(0.5)$ & -0.57 & 7.43 & $(0.5)$ & 7.46 & $(0.5)$ & -0.02 & -0.55 & 1.56 \\
\hline Promotion & 253 & 6.15 & $(0.3)$ & 6.16 & $(0.5)$ & -0.01 & 5.94 & $(0.3)$ & 6.08 & $(0.3)$ & -0.14 & 0.13 & 0.10 \\
\hline Quality of care & 254 & 6.43 & $(0.4)$ & 7.71 & $(0.4)$ & $-1.29^{* * *}$ & 6.95 & $(0.4)$ & 6.61 & $(0.4)$ & 0.34 & $-1.62^{*+*}$ & 12.37 \\
\hline Growth & 254 & 7.90 & $(0.2)$ & 8.25 & $(0.2)$ & -0.34 & 7.90 & $(0.2)$ & 7.35 & $(0.2)$ & $0.55^{*}$ & $-0.90^{* *}$ & 8.44 \\
\hline Contact colleagues & 254 & 8.93 & $(0.2)$ & 9.11 & $(0.2)$ & -0.18 & 9.23 & $(0.2)$ & 8.83 & $(0.2)$ & 0.41 & -0.58 & 3.39 \\
\hline Contact residents & 254 & 8.98 & $(0.2)$ & 9.56 & $(0.2)$ & $-0.59^{* *}$ & 8.99 & $(0.2)$ & 8.79 & $(0.2)$ & 0.20 & $-0.79^{* *}$ & 9.29 \\
\hline Total satisfaction (0-84) & 251 & 53.36 & $(0.97)$ & 56.41 & (1.6) & $-3.05^{* *}$ & 54.33 & $(1.6)$ & 52.87 & $(1.6)$ & 1.46 & $-4.50^{* *}$ & 8.19 \\
\hline \multicolumn{14}{|l|}{ Burnout (MBI-NL) } \\
\hline Emotional exhaustion ( $(\underline{0}-48)$ & 253 & 10.75 & $(0.8)$ & 8.31 & $(0.9)$ & $2.44^{* *}$ & 10.35 & $(0.8)$ & 10.77 & $(0.9)$ & -0.42 & $2.86^{*}$ & 6.52 \\
\hline Personal accomplishment $(0-\underline{42})$ & 253 & 28.10 & $(0.8)$ & 29.14 & $(0.7)$ & -1.05 & 26.38 & $(0.8)$ & 25.73 & $(0.7)$ & 0.65 & -1.70 & 2.11 \\
\hline
\end{tabular}

${ }^{*} p<005,{ }^{* *} p<001,{ }^{* * *} p<0001$.

The underlined scores indicate the most favorable score for the scale.

bScores in italics indicate a significant change in favor of the experimental group, meaning that the pre-/post change in the experimental group is significantly Scores in italics indicate a significant change in favor of the

different from the pre-/post change in the control group.
'Number of questionnaires included in the analysis $(N=256)$.

$\mathrm{GHQ}=$ General Health Questionnaire (short version).

MAS-GZ = Maastricht Work Satisfaction Scale for Healthcare

MBI-NL = Maslach Burnout Inventory (Dutch version).

$\chi^{2}(1)=$ chi square (1 degree of freodom). 